The Need for a Strong Science and Technology Program in the Nuclear Weapons Complex for the 21st Century

X. Garaizar

January 12,2010 
This document was prepared as an account of work sponsored by an agency of the United States government. Neither the United States government nor Lawrence Livermore National Security, LLC, nor any of their employees makes any warranty, expressed or implied, or assumes any legal liability or responsibility for the accuracy, completeness, or usefulness of any information, apparatus, product, or process disclosed, or represents that its use would not infringe privately owned rights. Reference herein to any specific commercial product, process, or service by trade name, trademark, manufacturer, or otherwise does not necessarily constitute or imply its endorsement, recommendation, or favoring by the United States government or Lawrence Livermore National Security, LLC. The views and opinions of authors expressed herein do not necessarily state or reflect those of the United States government or Lawrence Livermore National Security, LLC, and shall not be used for advertising or product endorsement purposes.

This work performed under the auspices of the U.S. Department of Energy by Lawrence Livermore National Laboratory under Contract DE-AC52-07NA27344. 


\section{The Need for a Strong Science and \\ Technology Program in the Nuclear Weapons Complex for the $21^{\text {st }}$ Century}

Xabier Garaizar

July 2, 2009 


\section{The Need for a Strong Science and Technology Program}

\section{in the Nuclear Weapons Complex for the $21^{\text {st }}$ Century}

SUMMARY: In this paper I argue for the need for a strong Science and Technology program in the Nuclear Weapons Complex as the basis for maintaining a credible deterrence capability. The current Nuclear Posture Review establishes a New Triad as the basis for the United States deterrence strategy in a changing security environment. A predictive science capability is at the core of a credible National Nuclear Weapons program in the $21^{\text {st }}$ Century $^{1}$. In absence of nuclear testing, the certification of our current Nuclear Weapons relies on predictive simulations and quantification of the associated simulation uncertainties. In addition, a robust nuclear infrastructure needs an active research and development program that considers all the required nuclear scenarios ${ }^{2}$, including new configurations for which there is no nuclear test data. This paper also considers alternative positions to the need for a Science and Technology program in the Nuclear Weapons complex.

\footnotetext{
${ }^{1}$ Dimitri F. Kusnezov (2005): “National Nuclear Security Administration Advanced Simulation and Computing: Ushering in a New Decade of Predictive Capability". SC05 Supercomputing Conference, Seattle (17 November 2005): "In a post-testing era, we no longer have that luxury; calibrated models must be replaced by more predictive ones that demonstrate a basic understanding of the time evolution of a nuclear device, and ensure most accurate equations are modeled and implemented into the codes, that the models are validated with the best diagnostic data we can find, and that their implementation into the codes has been verified with analytic results, where possible."

2Tom D'Agostino's (NNSA Administrator) testimony to House Energy and Water Development Appropriations Subcommittee (21 May 2009). p 3 "NNSA will continue to pursue a modern more flexible Nuclear Security Enterprise that is significantly smaller than the Cold War complex, but is able to address a variety of stockpile scenarios." http://appropriations.house.gov/Witness testimony/EW/Thomas D Agostino 05 21 09.pdf
} 
From the moment the US ceased to be the only nuclear power, one of the major concerns in the US Nuclear Weapons Complex has been the need to maintain a credible deterrence capability. Through the years this position has been conditioned by a need to control and constrain the spread of nuclear weapons: the signing of the Non-Proliferation Treaty in 1968 including the call for disarmament ${ }^{3}$, multiple bilateral treaties (i.e., SALT, START) with the USSR/Russia, and more recently the signing (although not ratified) of the Comprehensive Nuclear-Test-Ban Treaty (CTBT) ${ }^{4}$ in 1996 and the Moscow (Strategic Offensive Reductions-SORT) Treaty in 2002.

The advent of a post cold-war era has not reduced the inherent uncertainties of nuclear deterrence. The transition from a bipolar USSR-US scenario to one that includes a third major (albeit considerably smaller) nuclear power in China together with the irruption of rogue states and non-state actors has increased the level of uncertainty and widened the array of possible adversaries against which to build a nuclear deterrence posture ${ }^{56}$

\footnotetext{
${ }^{3}$ Non-Proliferation Treaty, p 6: "Article VI: Each of the Parties to the Treaty undertakes to pursue negotiations in good faith on effective measures relating to cessation of the nuclear arms race at an early date and to nuclear disarmament, and on a treaty on general and complete disarmament under strict and effective international control." http://www.un.org/disarmament/WMD/Nuclear/pdf/NPTEnglish Text.pdf

${ }^{4}$ Comprehensive Nuclear-Test-Ban Treaty (CTBT) http://www.ctbto.org/fileadmin/content/treaty/treaty text.pdf. In early 1992, Congress initiated a one-year test moratorium by supporting the Hatfield amendment to the FY1993 Energy and Water Development Appropriations Bill, which (i) banned testing before July 1, 1993, (ii) set conditions on a resumption of testing, and (iii) banned testing after September 1996 unless another nation tested. President Bush signed the bill into law (P.L. 102-377) October 2, 1992. On July 3, 1993, President Clinton decided to extend the moratorium at least through September 1994 and subsequently extended the moratorium twice more past the September 1996 benchmark. From that point to this, while not officially a part of the comprehensive test ban treaty, or CTBT, the US Congress and each Administration has upheld P.L. 102-377 and supported the extension of the moratorium indefinitely

${ }^{5}$ Marvin Adams and Sidney Drell (2009). "Technical Issues in Keeping the Nuclear Stockpile Safe, Secure, and Reliable." Workshop on The Role of Nuclear Weapons in National Security Policy (sponsored by APS, AAAS, and CSIS) April 2008. p 3. http://www.lanl.gov/conferences/sw/2009/docs/technicallssues-nwstockpile-oct08.pdf ${ }^{6} 2002$ Nuclear Posture Review http://www.globalsecurity.org/wmd/library/policy/dod/npr.htm: "Terrorists or rogue states armed with weapons of mass destruction will likely test America's security
} 
Motivated by the CTBT and in response to the Fiscal Year 1994 National Defense Authorization

Act (Public Law 103-160), the Science-Based Stockpile Stewardship Program (SSP) ${ }^{7}$ was

established in 1995 with the mission to (in the absence of nuclear testing) predict, detect, and

evaluate potential problems of the aging stockpile; and maintain the science and engineering

institutions needed to support the nation's nuclear deterrent, now and in the future. ${ }^{8}$ The

Advanced Simulation and Computing $(\mathrm{ASC})^{9}$ Program has the responsibility to provide the simulation capabilities (hardware and software) to carry out the mission of SSP. These simulation capabilities, together with non-critical tests, are an integral part of today's assessment and certification of our current stockpile. ${ }^{10}$

The multi-physics codes used to certify the safety and reliability of the nation's nuclear stockpile are required to rely less on phenomenological models calibrated to underground test

commitments to its allies and friends. In response, we will need a range of capabilities to assure friend and foe alike of U.S. resolve"

${ }^{7}$ The Stockpile Stewardship and Management Program. Maintaining Confidence in the Safety and Reliability of the Enduring U.S. Nuclear Weapon Stockpile (http://www.learnworld.com/ZNW/LWText.DOE.Stockpile.html)

${ }^{8}$ Office of the Deputy Assistant to the Secretary of Defense for Nuclear Matters (OSD): "The Stockpile Stewardship Program was established in response to the Fiscal Year 1994 National Defense Authorization Act (Public Law 103160), which requires, in the absence of nuclear testing, a program to: 1. Support a focused, multifaceted program to increase the understanding of the enduring stockpile; 2. Predict, detect, and evaluate potential problems of the aging of the stockpile; 3 . Refurbish and re-manufacture weapons and components, as required; and 4. Maintain the science and engineering institutions needed to support the nation's nuclear deterrent, now and in the future. http://www.acq.osd.mil/ncbdp/nm/USNuclearDeterrence.html

${ }^{9}$ The original Accelerated Strategic Computing Initiative (ASCI) was renamed in 2005 as the Advanced Simulation and Computing Program and remains part of the National Nuclear Security Administration (NNSA)

${ }^{10}$ Supra OSD: "Assessment and Certification. Assessments of the safety and performance of stockpiled weapons and actions taken to modify them must be based on demonstrated performance. That is, the assessments must be grounded on existing nuclear test data, nonnuclear tests, fundamental science experiments, and simulations using validated computer models. To the extent possible, nonnuclear tests are used to assess weapon safety and performance and, together with past nuclear test results, are used to validate computer simulations. Once validated to the extent possible, these simulations guide expert judgments about stockpile issues.

Such demonstration-based assessments underpin both the certification of a refurbished weapon system and the Annual Assessment Review. Mandated by law, this annual certification of the stockpile is based on the technical evaluations made by the national laboratories and on advice from the three laboratory directors, the Commander of U.S. Strategic Command, and the Nuclear Weapons Council. 
(UGT) data and more on models that incorporate an understanding of the time evolution of a nuclear device. In addition, these numerical simulations need to satisfy the rigorous process of Quantification of Margins and Uncertainties ${ }^{11}$, being able to quantify and reduce simulation uncertainties from all sources and aggregate these to an overall simulation uncertainty. These are the characteristics of a predictive simulation capability

As part of an expanded mission in the ASC program $^{12}$, predictive simulation capabilities are used on broader national security applications in collaboration with other government agencies such as the Department of Defense (DoD), Department of Homeland Security (DHS), and Defense Threat Reduction Agency (DTRA). In particular the ASC predictive codes will address modifications to current weapon designs or develop new ones (if and when necessary) for the stockpile of the future; help understand the effects of the detonation of devices from a diversity of designs; and assist in the forensic efforts to identify the origin of a detonated or interdicted device and of its components and fuel.

In order to satisfy all these national needs, a strong emphasis in Science and Technology for the Nuclear Weapons Complex is predicated on a reversal of the existing trend in the Stockpile Stewardship Program ${ }^{13}$. This proposal is in line with the existing Nuclear Posture Review and its need to maintain a credible deterrence based on the following points:

\footnotetext{
${ }^{11}$ For an overview of QMU as applied to the Nuclear Weapons complex, we refer to the Jason report led by D. Eardley "Quantifications of Margins and Uncertainties (QMU). Jason report JSR-04-330 (23 March, 2005) and David H Sharp and Merri M. Wood-Schultz. (2003) QMU and Nuclear Weapons Certification. Los Alamos Science \# 28, 2003. http://www.fas.org/sgp/othergov/doe/lanl/pubs/las28/sharp.pdf.

12 Advanced Simulation \& Computing ROADMAP (http://www.sandia.gov/NNSA/ASC/pdfs/ASC-RdMap1206r.pdf) p iii, 6

${ }^{13}$ The budget of the Office of Advanced Simulation and Computing in NNSA Defense Programs has been reduced $23 \%$ from \$721.4M in FY2004 to \$556.1 in FY2009 (in absolute dollars, not adjusted for inflation)
} 
(a) Certification and assessment of the safety and reliability of today's stockpile for the immediate future.

(b) Strengthening the current US Nuclear Warhead Infrastructure.

(c) Attribution of the origin of non-state nuclear devices and their components.

In addition to a better understanding of material properties, this emphasis in Science and Technology includes research in Computer Science, Quantification of Uncertainties and robust numerical methods and algorithms applied to multi-physics multi-scale simulation codes that describe the processes during nuclear explosions.

CERTIFICATION. Today's simulation codes can be described as adequate to answer most of the current fundamental questions in the stockpile, when used in conjunction with the UGT data and non-critical experiments. There are several limitations that if not addressed will impact the ability to certify the current stockpile. First, as weapons age and move further away from the configurations used in nuclear tests prior to the CTBT, it will be necessary to rely more on the predictive character of the simulation and on noncritical experiments, increasing the importance of the uncertainty quantification process and the additional accuracy of the physics models and algorithms. Second, full-physics simulations in two space dimensions are considered routine today, but simulations in three space dimensions take days or weeks in the National Nuclear Security Administration's (NNSA) fastest supercomputers. This is far from the desired quick turnaround for predictive science because the quantification of uncertainties requires running hundreds or thousands of simulations ${ }^{14}$. Third, existing ASC simulation codes were designed for the supercomputers of the late 90's, with architectures based primarily on

\footnotetext{
${ }^{14}$ Marvin Adams and Sidney Drell (2008) p 7.
} 
single core processor technology. The supercomputers expected for the next 10-20 years will

have 128 (or even more) cores per processor and lower ratio of memory per core. ${ }^{15}$ This type of computer architecture, quite different from what the current codes were designed for, will stress code performance: at best limiting the benefit obtained from the increase in computing performance (measured in peta- and exa-flops ${ }^{16}$ ) of the new supercomputers, and at worst degrading the performance due to incompatibilities with code design.

These limitations point to the need to introduce new algorithms and programming models that enhance the accuracy, scalability and time to solution of the simulation codes (to peta- and exascale computing); incorporate better physics models; and deliver advanced capabilities for QMU and uncertainty quantification ${ }^{1718}$. In regard to simulation software capabilities NNSA's current priorities are the maintenance and minor further development of existing simulation codes, focusing on their use to current Directed Stockpile Work requirements: resolution of Significant Finding Investigations (SFIs) and support of the Stockpile Life Extension Programs

\footnotetext{
${ }^{15}$ A Platform Strategy for the ASC Program (http://www.sandia.gov/NNSA/ASC/pdfs/AscPlatform2007.pdf) p 24: "Specifically, this means that processors will increase from dual core today to have 32, 128, or even more cores. The development of next-generation system architectures and a bridge to the ASC investment in distributed memory (MPI) applications must acknowledge and address this forecast."

${ }^{16}$ Ibid $\mathrm{p}$ 13. FLOPS (FLoating point Operations Per Second) is a measure of computing performance, floating point calculations. 1 petaflop $=10^{5} \mathrm{FLOPS}, 1$ exaflop $=10^{8} \mathrm{FLOPS}$. The current highest performing computer in the Weapons Complex is Roadrunner at Los Alamos, rated at approximately 1 petaflop

${ }^{17}$ Marvin Adams and Sidney Drell (2008), p 7: Model implementation into software is more challenging today than in past decades because of the complexity of the computing hardware on which the software must operate. .... For such platforms, successful implementations of mathematical models of physical phenomena require integrated efforts by teams with expertise in theory, discretization techniques, iterative methods, and computer science.

18 John A. Gordon (2002), DoE Under Secretary for Nuclear Security and NNSA Administrator, statement before Senate Committee on Armed Services http://armed-services.senate.gov/statemnt/2002/Gordon.pdf, p 4.
} 
(SLEPs). Under declining budgets ${ }^{19}$, these priorities imply a sharp reduction in research of new simulation technologies.

INFRASTRUCTURE. The United States is the only one of the five original Nuclear Powers without an active modernization program. Russia continues to modernize its strategic nuclear forces and maintains a fully functional nuclear weapons design program. ${ }^{20}$ China is not only in a modernization path but is actually "expanding the size of its nuclear arsenal. It is qualitatively and quantitative modernizing its nuclear forces ${ }^{\prime 21}$. Our allies are also adapting to the new security environment, in the case of the United Kingdom investing in sustaining capabilities that ensure a viability of developing replacement warhead types if necessary, and in the case of France maintaining a fully functional and active nuclear warhead design. ${ }^{22}$

The Nuclear Posture Review identifies dissuasion ${ }^{23}$ as one of the contributions of the New Triad, in particular as a result of maintaining a responsive nuclear infrastructure. This will be achieved by complementing the industrial component of the infrastructure with personne ${ }^{24}$ of the requisite expertise: design, basic science, computational simulation and experimentation

\footnotetext{
${ }^{19}$ The Office responsible for producing these capabilities is the Office of Advanced Simulation and Computing in NNSA Defense Programs. Its budget (in absolute dollars, not adjusted for inflation) has been reduced $23 \%$ from $\$ 721.4 \mathrm{M}$ in FY2004 to \$556.1 in FY2009

${ }^{20}$ Samuel W. Bodman and Robert M Gates (2008) National Security and Nuclear Weapons in the 21st Century http://www.defenselink.mil/news/nuclearweaponspolicy.pdf, pp7-8

${ }^{21} \mathrm{Ibid}, \mathrm{p} 6$

${ }^{22}$ Ibid, $p$

${ }^{23} 2002$ Nuclear Posture Review http://www.globalsecurity.org/wmd/library/policy/dod/npr.htm: "The capacity of the infrastructure to upgrade existing weapon systems, surge production of weapons, or develop and field entirely new systems for the New Triad can discourage other countries from competing militarily with the United States." ( $p$ 14)

${ }^{24}$ Marvin Adams and Sidney Drell (2008) p5 "Expert personnel constitute more of a deterrent to evolving threats than do facilities or even existing weapons. Given sufficient resources, people with the appropriate expertise can respond quickly to unanticipated problems or changes in requirements and can provide confidence in the solutions they produce. Without such people, no amount of resources will yield timely solutions, in which confidence is justified, to new problems."
} 
among others ${ }^{2526}$. A Science and Technology Program is required to maintain an agile infrastructure capable to respond to emerging threats, anticipating innovations by the adversary and countering them before our deterrence is degraded. ${ }^{27}$ As Keith Payne writes, "The seeds of dissuasion must be sown in advance of the manifest appearance of threat". ${ }^{28}$

ATTRIBUTION and FORENSICS. When dealing with rogue states and non-state actors, deterrence takes a different character: the need to identify the origin of an interdicted or detonated nuclear device as well as of its components and fuel. Some of the specific needs in the S\&T area are: (i) computational codes that can simulate non-US designs on a wide range of scenarios, (ii) a full understanding of the nuclear cycle from cradle to grave (for example, how different processing techniques determine material signatures of fuels, creating a comprehensive database of such signatures that can be contrasted to interdicted fuel) and (iii) accounting for all physical processes that occur post detonation, aiding in forensic analysis and civic response readiness. Being able to identify the country of origin of devices, components or fuel found in the hands of a non-state actor is a powerful deterrent; an incentive for the countries of origin to make sure that their nuclear stockpile does not suddenly appear in the wrong hands.

\footnotetext{
${ }^{25}$ Marvin Adams and Sidney Drell (2008) p 4

${ }^{26}$ John Browne et al (December 2008) "Nuclear Weapons in the $21^{\text {st }}$ Century US National Security" Report by a joint Report by a Joint Working Group of AAAS, the American Physical Society, and the Center for Strategic and International Studies. http://www.aps.org/policy/reports/popa-reports/upload/nuclear-weapons.PDF p 10:

"Scientific and technical expertise is crucial to sustain the nuclear weapons mission. This can be enabled through a broad range of nuclear-related research and development activities.

27 John A. Gordon (2002), p 4

${ }^{28}$ Keith Payne (2009) How Much is Enough?: A Goal-Driven Approach to Defining Key Principles http://www.lanl.gov/conferences/sw/2009/docs/payne livermore-2.pdf
} 
These are examples of national security challenges better addressed by the nuclear weapons community ${ }^{29}$ and requiring a strong Science and Technology program. This far, I have presented a case for the development of a Strong Science and Technology program in the Nuclear Weapons Complex, which would address the simulation capability aspects and reside primarily to the NNSA (Nuclear Weapons) Laboratories, reversing the current budget trend in the Nuclear Weapons Complex. There are other views in the scientific community which range from an assertion that there is no need for an S\&T program to a debate about where such a program should reside. The three more commonly encountered alternative opinions are:

(a) Under the current treaties with Russia, in addition to the deployed warheads, we maintain a sizeable stock of warheads that can be brought into use as needed, thus obviating the need for an active R\&D effort to back the currently deployed stockpile and maintain a deterrence strategy.

(b) If there is a need to manufacture new warheads, we can go back to building systems that were tested, using the blueprints of existing designs. This position accepts a requirement for manufacturing capabilities (industrial infrastructure) but not for research.

(c) We can maintain a strong research and development effort at the DoE Office of Science (SC) and the National Science Foundation (NSF), tapping on the strengths of American universities. Since most of the research required for the Nuclear Weapons Program is of

\footnotetext{
${ }^{29}$ Tom D'Agostino's (NNSA Administrator) testimony to House Armed Services Committee (27 February 2008) "In addition, our $21^{\text {st }}$ century enterprise will continue to leverage the scientific underpinnings of the historic nuclear weapons mission to respond to a full range of national security challenges that we have, and beyond nuclear weapons sustainment but shift those more towards nuclear counterterrorism and nuclear nonproliferation activities."
} 
dual use, Science and Technology advances incubated at DoE-SC and NSF can transition to the Nuclear Weapons Program as needed, avoiding duplication and increasing the returnon-investment.

These are all powerful arguments but they fall short under scrutiny.

(a) Reliance on the stored non-deployed warheads. In a stockpile of stable non-decaying confidence, this path would offer a replacement policy and even an argument to compensate for a degraded yield in current weapons by multiplying the number of warheads to be used. However this path addresses neither the issue of system confidence, the possibility of a catastrophic failure of a deployed warhead type ${ }^{30}$ ("would this system work at all regardless of yield?"); nor the gradual effect of aging in warheads: as they go through successive efforts at extending their service life, they deviate further and further from the baseline designs validated using nuclear testing ${ }^{31}$ and the effects of cumulative modifications ${ }^{32}$ could make the design obsolete. In addition, it does not address either the fact that as our adversaries (and allies) continue on a path of modernization, we will be maintaining a larger but qualitatively inferior stockpile. Finally, the cost of maintaining an aging stockpile increases at an alarming rate.

(b) Reliance on a manufacturing infrastructure. The United States has not designed a nuclear warhead since the 1980s and has not built a new one since the early $1990 \mathrm{~s}^{33}$. As stated above, if the United States relies in 1980s design for its stockpile while Russia, China, United

\footnotetext{
30 John A Gordon, DoE Under Secretary for Nuclear Security and NNSA Administrator, statement before Senate Committee on Armed Services http://armed-services.senate.gov/statemnt/2002/Gordon.pdf, p 4

${ }^{31}$ Samuel W. Bodman and Robert M Gates (2008), p 2

${ }^{32}$ Marvin Adams and Sidney Drell (2009). p 2

${ }^{33}$ Samuel W. Bodman and Robert M Gates (2008), p 19
} 
Kingdom and France pursue a path of modernization and new designs, it will be putting its faith on a qualitatively inferior stockpile. In addition the existing "blueprints" might rest in the use of materials and practices that are not allowable or feasible today due to safety and environmental concerns. When the Nuclear Posture Review identifies a "responsive defense infrastructure" as the third leg of the Triad ${ }^{34}$, it includes the need to consider the ability to design, develop, manufacture, and certify new warheads in response to new national requirements ${ }^{35}$. Thus we cannot expect that simply replicating production of tested designs will suffice to satisfy the NPR.

(c) Reliance on S\&T programs at DoE-SC and NSF. This is perhaps the most powerful argument of the three, because it contains a component of truth: some of the research required by the SSP and ASC programs is indeed dual use. In fact the ASC program has gone to great lengths to reach out to academia and build bridges that facilitate the use of technologies developed at the Office of Science Laboratories and Universities by the Code groups at the NNSA Laboratories. The Predictive Science Academic Alliance Program ${ }^{36}$ (PSAAP),

\footnotetext{
${ }^{34} 2002$ Nuclear Posture Review http://www.globalsecurity.org/wmd/library/policy/dod/npr.htm: "A revitalized defense infrastructure that will provide new capabilities in a timely fashion to meet emerging threats" 35 ibid "The need is clear for a revitalized nuclear weapons complex that will: ....be able, if directed, to design, develop, manufacture, and certify new warheads in response to new national requirements; and maintain readiness to resume underground nuclear testing if required."

${ }^{36}$ PSAAP http://www.sandia.gov/NNSA/ASC/univ/psaap.html. The primary goal of the Predictive Science Academic Alliance Program (PSAAP) is to establish validated, large-scale, multidisciplinary, simulation-based "Predictive Science" as a major academic and applied research program, training the next generation workforce. The PSAAP centers will develop not only the science and engineering models and software for their large-scale simulations, but also methods associated with the emerging disciplines of verification and validation and uncertainty quantification. Mechanisms are develop to ensure a two way communication with the NNSA laboratories, ensuring that progress in the areas listed above at the centers make their way into the Laboratories and vice versa.
} 
collaborations in the area of uses of High Performance Computing (HPC) and the ASC Institutes at each of the NNSA Laboratories ${ }^{37}$ are some of the examples in this area.

The problem with this approach is that the science relevant to the NSF and DoE-SC does not replicate the extreme conditions present in the complex systems that model Nuclear Weapons ${ }^{3839}$, and therefore the leveraged work, although important, is of limited value.

In conclusion, a strong Science and Technology program in the Nuclear Weapons Complex is required in order to support a credible nuclear deterrence strategy. This requirement arises from the mandate to certify and asses the nuclear stockpile, the rebuilding of a robust and responsive nuclear warhead infrastructure (as called for in the Nuclear Posture Review) and the need to deter rogue states and non-state actors from using or proliferating nuclear weapons and/or materials. Although a component of the most basic research and development in such Science and Technology program could be carried out at non-NNSA research centers (DoE-SC Laboratories and Universities), a vast range of activities and research require the expertise of personnel involved in the Nuclear Weapons Complex.

\footnotetext{
37 Institute for Terascale Simulation at Lawrence Livermore National Laboratory, The Computer Science Research Institute at Sandia National Laboratory and The Los Alamos Computer Science Institute at Los Alamos National Laboratory.

${ }^{38}$ William J. Perry and James R. Schlesinger. (2009) America's Strategic Posture, pp 51-52:" Nuclear weapons are exceptionally complex, involving temperatures as high as the sun and times measured in nanoseconds. Understanding these weapons from first principles requires a broad, diverse and deep set of scientific skills ... Academic research cannot operate on the scale comparable to the weapons laboratories and industry has largely abandoned basic research in the physical sciences." http://media.usip.org/reports/strat posture report.pdf ${ }^{39}$ Marvin Adams and Sidney Drell (2009) p 5: "Because of the extreme conditions generated during a nuclear explosion and the myriad phenomena that simultaneously occur, the expertise required to answer stockpile questions is broad, deep, and often unique to nuclear weapons. This expertise is best obtained by dedicated personnel who devote the bulk of their careers to nuclear weapons."
} 